\title{
USE OF FUZZY LOGIC SYSTEMS FOR ASSESSMENT OF PRIMARY FAULTS
}

\author{
Ivica Petrović $^{*}$ - Lajos Jozsa ${ }^{* *}$ - Zoran Baus ${ }^{* *}$
}

\begin{abstract}
In electric power systems, grid elements are often subjected to very complex and demanding disturbances or dangerous operating conditions. Determining initial fault or cause of those states is a difficult task. When fault occurs, often it is an imperative to disconnect affected grid element from the grid. This paper contains an overview of possibilities for using fuzzy logic in an assessment of primary faults in the transmission grid. The tool for this task is SCADA system, which is based on information of currents, voltages, events of protection devices and status of circuit breakers in the grid. The function model described with the membership function and fuzzy logic systems will be presented in the paper. For input data, diagnostics system uses information of protection devices tripping, states of circuit breakers and measurements of currents and voltages before and after faults.

K e y w o r d s: fuzzy logic, primary faults, transmission grid
\end{abstract}

\section{Nomenclature}

$|\Delta I|-$ absolute value of current change sensitivity

$I_{t}-$ current after the event

$I_{n}$ - current value before the event

$\Delta U$ - absolute value of voltage change sensitivity

$U_{t}$ - voltage after the event

$U_{n}$ - voltage value before the event

$X_{i i}^{y}$ - output variable

\section{INTRODUCTION}

In many papers based on this topic, the primary goal is to determine the fault location in the grid, features of the grid, its protection and the automatization [1-3]. Functions of fault locations and basic methods for determining fault locations in transmission grid are described $[11,13]$. The overview of specific factors which affect fault locations is often shown $[2,10,17]$.

Very few researchers are working on determining and analyzing primary events when complex or multiple faults occurred using standard methods.

The literature often describes component methods for fault location in transmission and distribution grids: fault indicators, fault location software and statistical analysis of fault frequency [8]. Other aspects are also described, such as fault diagnostics and data on practically implemented techniques for fault location [6]. In distribution grids, the fault location is often done using software algorithms which have been developed in the last few years.
The article describes problems in determination and analysis of primary events for complex faults. The second section describes primary fault and its state in electrical power system. The third section contains an overview of faults and unforeseen events on grid elements. The fourth section contains synthesis of fuzzy regulator for primary faults and unforeseen events on grid elements. The fifth section describes test case of a real event in electrical power grid.

\section{DETERMINING PRIMARY FAULT IN THE GRID BY SYSTEM OPERATION AND CONTROL}

The analysis of initial cause of disturbance or fault is based on the change in grid topology and states of protection devices using SCADA system. Data classification is based on different chronology, alarm and event lists from which relevant data is derived for event analysis.

The most common faults in the grid are short circuits, and their effects are forbidden changes in current and voltage in affected point in the grid. These effects threaten grid elements and prevent power feed to consumers.

In real time immediately after unforeseen event or fault, System Operation and Control takes action based on chronology, alarm and event lists, states of protection devices and circuit breakers, and current and voltage data from SCADA system. All gathered data with one-line diagram of the grid lead to conclusions of the fault. Modern SCADA system is very complex as shown in Fig. 1.

\footnotetext{
* Croatian Transmission System Operator Ltd, Kupska 4, 10000 Zagreb ** Power System Engineering Department at Faculty of Electrical Engineering in Osijek, Croatia, zoran.baus@etfos.hr, lajos.jozsa@etfos.hr
} 


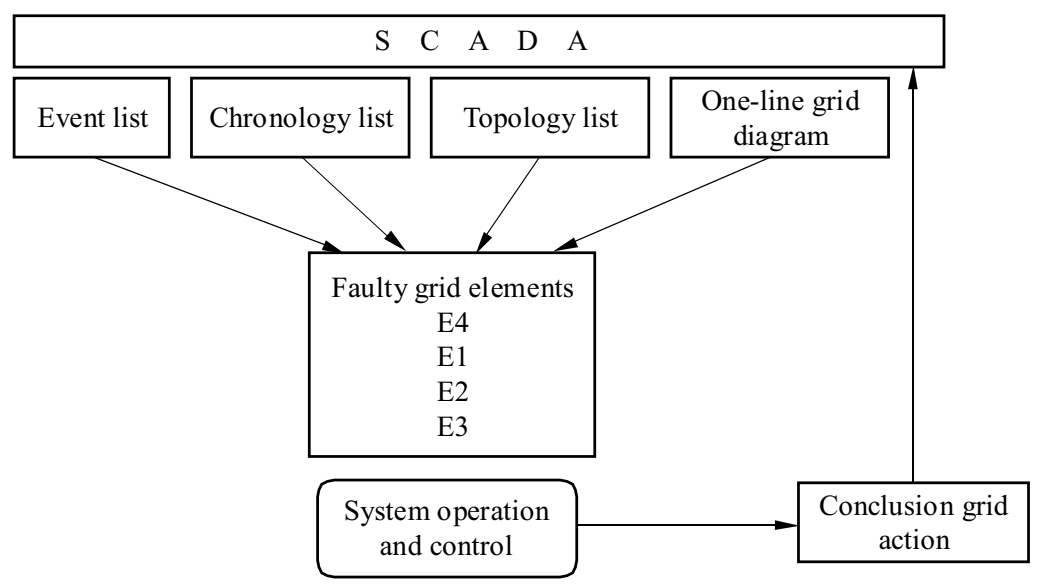

Fig. 1. Block diagram of data gathering and decision making of SCADA

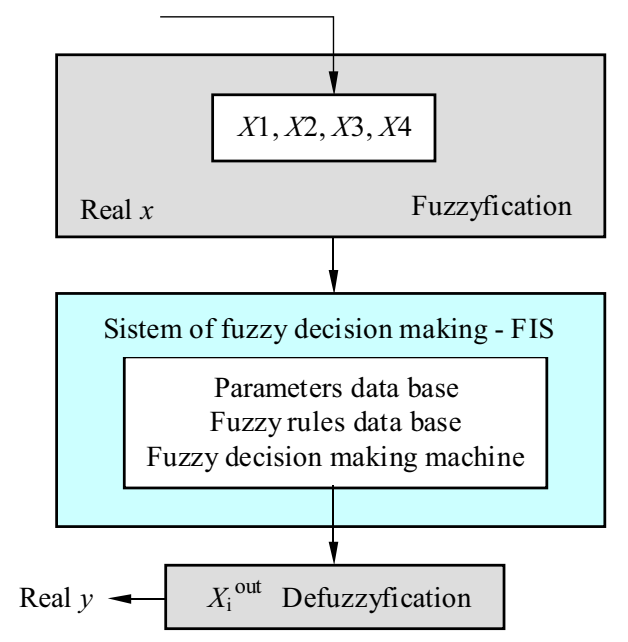

Fig. 2. Block diagram of fuzzy regulator

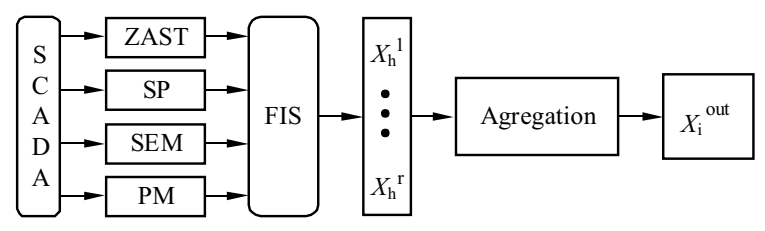

Fig. 3. The overview of complete fuzzy system

The final decision making is always dependent on knowledge and experience of System Operation and Control.

In complex and multiple faults, determination of the primary fault is a big challenge because of errors in determining the exact time of single faults in all affected grid knots. These errors can cause wrong decision to be made, if wrong primary fault is selected.

\section{FAULTS AND UNFORESEEN EVENTS ON GRID ELEMENTS}

To determine the initial cause of an unforeseen event is a tall order. Almost all faults in the power grid can be described with change of listed parameters and values:

- change of circuit breaker state (on transmission line, generator or transformer field),

- change of flux or current on grid element (values span from zero/low, normal to overload), also direction of current (positive or negative change),

- change of voltage on grid element (values span from zero/low, normal to high),

- alarm or trip of protection devices.

From listed parameters, the cause of almost every momentary or permanent fault can be determined. In order to determine the fault location and to form primary fault diagnostic system, the following parameters and information must be gathered:

- generator (circuit breaker state, current flow),

- transmission line (circuit breaker state on each side, current flow),

- bus bar (voltage change or value),

- load (circuit breaker state, current flow).

The listed parameters and information are necessary but sufficient to conclude the cause and time of the fault in all grid elements. From this information, the initial cause of fault can be found using fuzzy regulator.

\section{SYNTHESIS OF FUZZY REGULATOR}

During synthesis, the designer must describe rules for output change in respect to input change. Fuzzy rules are always conditional statements in which the causing part presents condition in application domain, and the consequence part presents control of the managed system. These rules can be attained by experience, that is by observing an experienced operator in a dynamic process. 


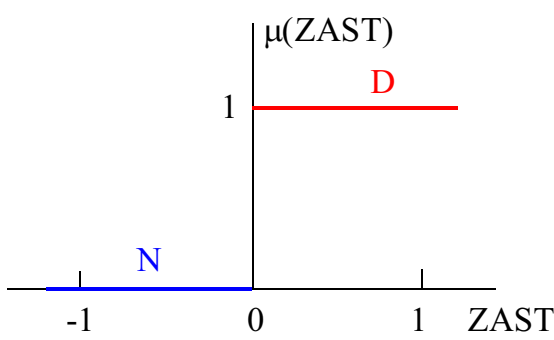

Fig. 4. Membership function ZAST

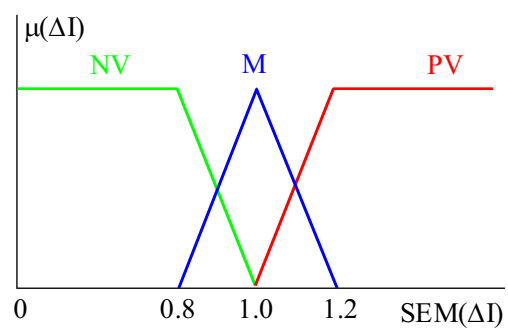

Fig. 6. Membership function ZAST

The core knowledge in expert fuzzy systems contains knowledge expressed by fuzzy logic with indicated input variables and subscripts denoted as $\left(X_{1}, X_{2}, X_{3}\right.$, and $\left.X_{4}\right)$. Following variables are described as:

- alarm or trip of protection - ZAST,

- circuit breaker state change - SP,

- grid element current - SEM,

- voltage change on grid element - PN.

Figure 2 represents a block diagram of fuzzy regulator with given input variables.

Four parameters above are divided in few categories, that is few values spans. Parameters $X_{1}$ and $X_{2}$ can have values of 0 or 1 in fuzzy system. Their membership functions can also have values of 0 or 1 , as each parameter is given two belonging functions of the fuzzy system .

Parameters $X_{1}$ and $X_{2}$ can have values between 0 and 1 in the fuzzy system. Within this same system, each parameter can have few values, or few membership functions.

Figure 3 shows fuzzy system for determining the primary fault in the power system.

\subsection{Input variables and membership functions}

For complete understanding of the fuzzy system construction and conclusion, it is necessary to determine and describe every variable and its corresponding membership function.

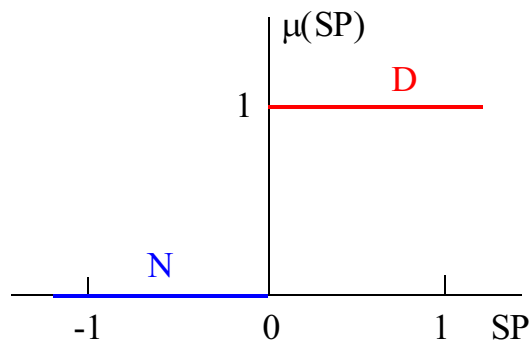

Fig. 5. Membership function SP

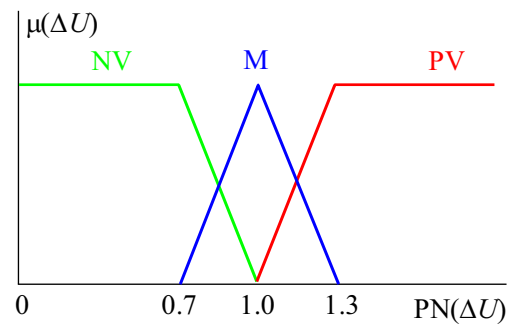

Fig. 7. Membership function SP

\section{Alarm or trip of protection - ZAST}

The first variable of the fuzzy regulator denoted with ZAST gives value determined by the state of protection device. In this scenario, two states are possible:

Steady state, which characterizes no change in the state of protection device.

Altered state, which characterizes a change caused by alarm or trip of protection device.

The graph of membership function ZAST is shown, in Fig. 4. Value 0 corresponds to the steady state, whereas the alarm or trip state is shown by value 1 .

\section{Circuit breaker state change - SP}

The second variable of fuzzy regulator denoted with SP represents value determined by the state of the circuit breaker. In this scenario, two states are possible:

- Steady state, which characterizes no change in the state of the circuit breaker.

- Altered state, which characterizes a change in the state of the circuit breaker.

The graph of membership function SP is shown in Fig. 5. The value 0 corresponds to the steady state, while value 1 is allocated to a change in the state of the circuit breaker.

\section{Grid element current - SEM}

The third variable of fuzzy regulator denoted with SEM and represents the value of change in the current of the grid element. In order to determine the current 
change throughout the grid element, it is necessary to define and determine sensitivity indexes of the change in the current in the existing grid element.

If the absolute value of current change sensitivity is denoted by $|\Delta I|$ and defined by the change of current in a certain grid element in respect to the current value before the fault on unforeseen event, then the absolute value of current change sensitivity is defined as

$$
|\Delta I|=\left|\frac{I_{t}-I_{n}}{I_{n}}\right|
$$

where $I_{t}$ represents current after the event and $I_{n}$ represents current value before the event. If values of absolute sensitivity have values

$$
|\Delta I|=\left|\frac{I_{t}-I_{n}}{I_{n}}\right|>1,
$$

then the current value increases through the grid element, and reaches the fault current, which signifies that there is a great positive change in the fault current.

If values of absolute sensitivity have values

$$
|\Delta I|=\left|\frac{I_{t}-I_{n}}{I_{n}}\right|<1,
$$

then the current value decreases through the grid element, and reaches the value of zero, which signifies that there is a great negative change in the fault current.

If, on the other hand,

$$
|\Delta I|=\left|\frac{I_{t}-I_{n}}{I_{n}}\right| \approx 1
$$

then here is no significant current change in the grid system; that is, the current shows small and slow changes.

The corresponding membership function is shown in Fig. 6, where NV denotes a high negative sensitivity, $\mathrm{M}$ denotes a small sensitivity, and PV denotes a high positive sensitivity.

In this case, chosen values for absolute current change sensitivity and sensitivity indexes are as follows:

- If a value span of absolute current change sensitivity is from 0 to 1.0, sensitivity index is denoted by NV.

- If a value span of absolute current change sensitivity is from 0.8 to 1.2 , sensitivity index is denoted by M.

- If a value span of absolute current change sensitivity is higher than 1.2, sensitivity index is denoted by PV.

\section{Voltage change on grid element - PN}

The fourth input variable of the fuzzy regulator is denoted by $\mathrm{PN}$ and gives the value of change in the voltage of grid element. In order to determine the voltage change on the grid element, it is necessary to define and determine sensitivity indexes regarding the voltage change through the grid element. If the absolute value of voltage change sensitivity is denoted by $|\Delta U|$, it is defined by the change of voltage at the certain grid element in respect to voltage value before the fault on unforeseen event. The absolute value of voltage change sensitivity is then defined as

$$
|\Delta U|=\left|\frac{U_{t}-U_{n}}{U_{n}}\right|,
$$

where $U_{t}$ represents voltage after the event and $U_{n}$ represents voltage value before the event. If values of absolute sensitivity

$$
|\Delta U|=\left|\frac{U_{t}-U_{n}}{U_{n}}\right|>1,
$$

then there is an increase in the voltage on the grid element, which means that there is a greate positive voltage change.

If absolute sensitivity

$$
|\Delta U|=\left|\frac{U_{t}-U_{n}}{U_{n}}\right|<1,
$$

then there is a decrease in the voltage on the grid element, and voltage reaches the value of zero, which signifies a great negative voltage change.

Lastly, in the third case, if

$$
|\Delta U|=\left|\frac{U_{t}-U_{n}}{U_{n}}\right| \approx 1,
$$

then there is no significant voltage change in the grid element, or voltage change is small and slow along with its memebership function.

The corresponding membership function is shown in Fig. 7. The sensitivity index defined by NV denotes a high negative sensitivity, $\mathrm{M}$ denotes a small sensitivity, and PV denotes a high positive sensitivity.

In this case, chosen values for absolute voltage change sensitivity and sensitivity index are as follows:

- If a value span of absolute voltage change sensitivity is from 0 to 1.0, sensitivity index is denoted by NV.

- If a value span of absolute voltage change sensitivity is from 0.7 to 1.3 sensitivity index is denoted by M.

- If a value span of absolute voltage change sensitivity is higher than 1.3, sensitivity index is denoted by PV.

\subsection{Decision making rules data base and assess- ment of primary fault}

Fuzzy system rules data base is dependent on knowledge and experience of operator-expert. Rules are determined and stored in few basic guidelines for different grid elements. 


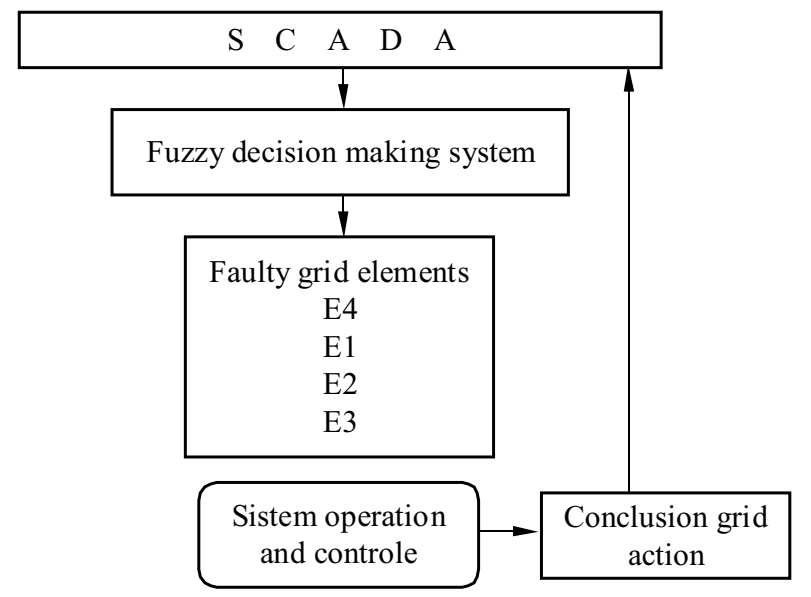

Fig. 8. Block diagram of information processing and decision making in modern SCADA system using fuzzy logic for primary fault assessment

Table 1. Example of decision making of fuzzy system for assessment of primary fault on one grid element

\begin{tabular}{cccccc}
\hline Rule number & ZAST & SP & SEM & PN & $\begin{array}{c}\text { Output } \\
\text { variable } X_{l i}^{r}\end{array}$ \\
\hline 1 & D & D & PV & M & SK \\
2 & D & D & PV & NV & PK \\
3 & & & & & SK \\
4 & & & & & SK \\
$\vdots$ & & & & & \\
35 & & & & & NK \\
36 & & & & & NK \\
\hline
\end{tabular}

Table 2. Transforming output variables from fuzzy to express system

\begin{tabular}{ccccc}
\hline$X_{i}$ & PK & SK & TK & NK \\
\hline Express variable & 1 & 2 & 3 & 4 \\
\hline
\end{tabular}

1. Fault location decision making rules for transmission line

- No current, open circuit breaker, overload not registered $=$ fault on transmission line

- No current, open circuit breaker, overload registered $=$ shutdown caused by overload

- No current, closed circuit breaker = voltage collapse

- Too high power flow = overload

\section{Fault location decision making rules for bus bar}

- All circuit breakers in the node open, flow equals zero, voltage equals zero $=$ trip of bus bar protection

- Necessary signals = voltage
3. Fault location decision making rules for load

- No current, closed circuit breaker = load fault

- No current, open circuit breaker = grid fault

4. Fault location decision making rules for generator

- No current, closed circuit breaker = generator fault

- No current, open circuit breaker = grid fault

Based on these expert rules, decision making rules are derived for assessment of primary fault, simbolically shown in Tab. 1 . Data base has 36 rules $(2 \times 2 \times 3 \times 3$ states $)$.

From Tab. 1 it can be seen that the output variable $X_{i i}^{y}$ can have four states: PK (primary or initial fault), SK (secondary fault), TK (tertiary fault) and N (no fault). These four states can be denominated with numbers, as in Tab. 2.

Every tested or diagnosed grid element can have only one state, or value: $1,2,3$, or 4 . The final product is a list of elements $E_{1}, E_{2}, \ldots, E_{n}$, arranged from $1,2,3$, or 4, as follows

1. List with one element on which the primary fault occurred.

2. List of elements on which secondary faults occurred.

3. List of elements on which tertiary faults occurred.

4. List of elements with no faults.

Fault lists and primary fault assessment are done automatically based on already determined priorities and order, as shown in Fig. 8.

Using modern SCADA with fuzzy logic prevents human errors made by less experienced operators. The main advantage of the fuzzy system is that it enables fast information processing and gives an overview to expert operator for decision making.

\section{TEST MODEL OF PRIMARY FAULT ASSESSMENT ON COMPLEX EVENT}

In order to define the specific advantage of methods for determining the primary event, it is necessary to review it on a simple experimental example of the network with a complex event. Let us then consider a system where a very large number of consecutive interrelated consequently created events can be reviewed. In this case, the operator-expert is not able to quantify the events that emerged from the system in a short time due to the large number of events. In addition, it needs to determine the cause of the fault and determine the primary failure, and then take the steps to establish the normal state. Table 1 provides an overview of the list of events from SCADA with accompanying screen displays network status. This is the list of SCADA - KRD list - 530 events, which occurred in 4 minutes.

SCADA with S3 $110 \mathrm{kV}$ on the basis of the data obtained on the measurements, incentives and protection 
Table 3. A part of a complex event from the SCADA system

\begin{tabular}{cccc}
\hline Time & Location & Object & State event \\
\hline 0 & 1 & TR $1110 / 35 \mathrm{kV}$ & Switched off \\
0 & 2 & DV 1 & Switched off \\
0 & 3 & TR2 $110 / 35 \mathrm{kV}$ & Switched off \\
0 & 4 & TR2 $110 / 35 \mathrm{kV}$ & Switched off \\
$+1^{\prime}$ & 5 & DV 2 & Switched off \\
$+2^{\prime}$ & 6 & TR2 $110 \mathrm{kV}$ & $\begin{array}{c}\text { Switched off } \\
\text { Switched off }\end{array}$ \\
$+3^{\prime}$ & 7 & DV 3 & $\begin{array}{c}\text { Switched off Busbars } \\
\text { protection }\end{array}$ \\
$-4^{\prime}$ & 8 & TP $1400 / 110 \mathrm{kV}$ & $\begin{array}{c}\text { Switc } \\
\text { Switched off Busbars } \\
\text { protection }\end{array}$ \\
$-4^{\prime}$ & 8 & VP Damping Coil & $\begin{array}{c}\text { Switched off Busbars } \\
\text { protection }\end{array}$ \\
$-4^{\prime}$ & 8 & VP 1 & $\begin{array}{c}\text { Switched off Busbars } \\
\text { protection }\end{array}$ \\
$-4^{\prime}$ & 8 & VP 2 & $\begin{array}{c}\text { Switched off Busbars } \\
\text { protection }\end{array}$ \\
\hline
\end{tabular}

Table 4. A part of events to determine the primary event by using fuzzy system

\begin{tabular}{|c|c|c|c|c|}
\hline Time & Location & Object & State event & Priority \\
\hline$-4^{\prime}$ & 8 & $\mathrm{TP} 1400 / 110 \mathrm{kV}$ & $\begin{array}{c}\text { Switched off } \\
\text { Busbars protection }\end{array}$ & 1 \\
\hline$-4^{\prime}$ & 8 & $\begin{array}{l}\text { VP Damping } \\
\text { Coil }\end{array}$ & $\begin{array}{c}\text { Switched off } \\
\text { Busbars protection }\end{array}$ & 2 \\
\hline$-4^{\prime}$ & 8 & $\mathrm{VP} 1$ & $\begin{array}{c}\text { Switched off } \\
\text { Busbars protection }\end{array}$ & 2 \\
\hline$-4^{\prime}$ & 8 & VP 2 & $\begin{array}{c}\text { Switched off } \\
\text { Busbars protection }\end{array}$ & 2 \\
\hline$-4^{\prime}$ & 8 & VP 3 & $\begin{array}{c}\text { Switched off } \\
\text { Busbars protection }\end{array}$ & 2 \\
\hline 0 & 1 & TR 1 110/35 kV & Switched off & 3 \\
\hline 0 & 2 & DV 1 & Switched off & 3 \\
\hline 0 & 3 & TR2 110/35 kV & Switched off & 3 \\
\hline 0 & 4 & TR2 110/35 kV & Switched off & 3 \\
\hline$+1^{\prime}$ & 5 & DV 2 & Switched off & 3 \\
\hline$+2^{\prime}$ & 6 & $\mathrm{TR} 2110 \mathrm{kV}$ & Switched off & 3 \\
\hline$+3^{\prime}$ & 7 & DV 3 & Switched off & 3 \\
\hline
\end{tabular}

activities and indications on the state of devices, we have information on the following sizes

1. The voltages at the network elements: $U_{l}=0.2 U_{n}$.

2. Electricity at the network elements $I_{s p}=14 \mathrm{kA}$, $I_{d v 1}=2 \mathrm{kA}, I_{d v 2}=2.5 \mathrm{kA}, I_{d v 3}=1.8 \mathrm{kA}$.

3. Situation of all system elements switches III $110 \mathrm{kV}$ bus off.

4. Effect of bus protection.

Based on these values of parameters we have following values in the fuzzy system for the characteristic elements of the network as shown below

1. Due to incentives or protective action (Fig. 4) $\mu(\mathrm{ZAST})_{n}=D$.
2. Due to changes in the state of switches (Fig. 5) $\mu(\mathrm{SP})_{n}=D$.

3. Due to the increase in current through the elements of the network (Fig. 6) $\mu(\Delta I)_{n} \geq 1$.

4. Due to voltage drop on the element of the network (Fig. 7) $\mu(\Delta U)_{n} \leq 1$.

If there are multiple network elements that meet the requirement of 5.1 , the primary event and the affected network element is determined by the highest value of $\mu(\Delta I)_{n}$. That is achieved in the event of bus protection action on some bus system. In all other cases, this condition is not met. For the above case, the following applies:

$$
\begin{array}{rlrl}
\mu(\mathrm{ZAST})_{n} & =D, & \mu(\mathrm{SP})_{n} & =D, \\
\mu(\Delta I)_{n} & \gg 1, & \mu(\Delta U)_{n} \leq 1 .
\end{array}
$$

Primary particular event is determined based on the rule of inference, and the output size will have a value of PK. This value, marked with PK in the fuzzy system, will be converted into a distinct with a value of 1 as it is defined in the Table. 2 .

All other values of fuzzy values that do not meet the criteria of 5.1 represent the secondary event or tertiary event in the power system. Finally, the established list of events will be determined and put together on a priority basis by applying the rule base of fuzzy logic. Table 4 provides an overview of a part of the list of events to determine the primary event with the application of fuzzy systems based on the information about the state of the network.

From a crowd of indiscriminately processed events, a very complex priority list of events in the network is established, without chronology. In this way, as shown, it is unequivocally pointed to a primary affected element of the network and a priority list of events is created.

\section{CONCLUSION}

Complex disturbances in power systems demand very difficult and fast actions by the operator, often beyond their capabilities. The existing methods for primary fault assessment are slow and unreliable.

By creating fuzzy system, it is possible to find primary fault from large number of alarms and events by organizing, quantifying and analyzing. Fuzzy system is based on linear membership functions. It allows correct and fast information on initial cause, which largely contributes to system security and reliability.

\section{REFERENCES}

[1] LEE, H. J.-AHN, B. S.-PARK, Y. M.: A Fault Diagnosis Expert System for Distribution Substations, IEEE Transactions on Power Delivery 15 No. 1, (2000), 92-97.

[2] YONGLI, Z.-YANG, Y. H.-HOGG, B. W.-ZHANG, W. Q.-GAO, S.: An Expert System for Power System Fault 
Analysis, IEEE Transactions on Power Systems 9 No. 1 (1994) 503-509.

[3] VAZQUEZ, M. E.-OSCAR, L.-CHACON, M.-HECTOR, J.-ALTUVE, F.: An On-Line Expert System for Fault Section Diagnosis in Power Systems, IEEE Transactions on Power Systems 12 No. 1 (1997), 357-362.

[4] LEE, J. W.-KIM, J. T.-PARK, J. C.-HWANG, I. K.-LYU, S. P.: Computer-Based Alarm Processing and Presentation Methods in Nuclear Power Plants, World academy of Science, Engineering and Technology, 2010.

[5] SAUVE, J. P.et al: Maintenance Techniques for Intelligent Alarm Processing System, vol. 13, CRL Publishing, Knowledge Engineering, 2005.

[6] TOMSOVIC, K.-LIU, C. C.-ACKERMAN, P.-POPE, S.: An Expert System as Dispatchers Aid for the Isolation of Line Section Faults, IEEE Power Engineering Review 7 No. 7 (1987), $51-52$.

[7] BALAKRISHNAN, R.-PAHWA, A.: A Computer Assisted Intelligent Storm Outage Evaluator for Power Distribution Systems, IEEE Transactions on Power Delivery 5 No. 3 (1990), 1591-1597.

[8] HSU, Y. Y.et al : An Expert System for Locating Distribution System Faults, IEEE Transactions on Power Delivery 6 No. 1 (1991), 366-372.

[9] SAJJA, P. S.-SHAH, D. M. : Knowledge Based Diagnosis of Abdomen Pain using Fuzzy Prolog Rules, Journal of Emerging Trends in Computing and Information Science 1 No. 2 (2010), 55-60.

[10] VALE, Z. A.-MOURA, A. M. : An Expert System Approach for Power System Diagnosis.

[11] GERS, J.-HOLMES, E. J.: Protection of Electricity Distribution Networks, 2nd edition, IEE the Institution of Electrical Engineers, London, 2004.

[12] LEONIDES, C. T. : Knowledge-Based Systems Techniques and Applications, vol. 1-4, Academic press, San Diego, 2000.

[13] VACHTSEVANOS, G.et al : Intelligent Fault Diagnosis and Prognosis for Engineering Systems, John Wiley \& Sons, New Jersey, 2006.

[14] MEZA, E. M.et al : Exploring Fuzzy Relations for Alarm Processing and Fault Location in Electric Power Systems, IEEE Porto Power Tech Conference, 2001
[15] TAN, J. C.-Crossley, P. A.-MClaren, P. G.: Fuzzy Expert System for On-Line Fault Diagnosis on a Transmission Network, IEEE, 2001.

16] SAHA, M. M.--IZYKOWSKI, J.-ROSOLOWSKI, E.: Fault Location on Power Networks, Springer-Verlag, London, 2010.

[17] CARMONA, C. J.et al : An Analysis on the Use of Pre-Processing Methods in Evolutionary Fuzzy Systems for Subgroup Discovery, Elseviere 39 No. 11 (2012), 404-412.

Received 8 January 2015

Ivica Petrović, PhD, was born on 26 December, 1964, in Klobuk (Bosnia and Herzegovina). Dr. Petrović received his Certificated Engineer's Degree in electrical power engineering in 2002, and The Master of Science Degree in 2008. He received his $\mathrm{PhD}$ degree in 2013 from Faculty of Electrical Engineering of the Josip Juraj Strossmayer, University of Osijek. For many years, he worked as an associate assistant at the Faculty of Electrical Engineering in Osijek on Electric power system operation courses. He is employed in Croatian Transmission System Operator at function of the manager for the Network Center Osijek.

Lajos Józsa, PhD, was born on 19 December, 1945, in Feketic (Serbia). He is full-time professor at the Faculty of Electrical Engineering of the Josip Juraj Strossmayer, University in Osijek (Croatia), and head of Department of Power Engineering. Dr. Józsa received his Certificated Engineer's Degree in electrical power engineering in 1972, the Master of Science Degree in 1978, and the Doctor of Philosophy Degree in 1984, all from the University in Zagreb (Croatia). His special fields of interest are operation, control and reliability of electrical power system.

Zoran Baus, PhD, was born on June 15, 1951. He obtained his BSc degree (1975), MSc degree (1987), in electrical engineering and his $\mathrm{PhD}$ degree from the Faculty of Electrical and Computing Engineering, Zagreb, Croatia in 2004. His major fields of interest include Intelligent Control (fuzzy control and optimization) and Power System Analyses. Presently, he is a Full-Time Professor at the Power System Engineering Department at Faculty of Electrical Engineering in Osijek, Croatia. 